\title{
Role of fragmentation in as-cast structure: numerical study and experimental validation
}

\author{
Yong-jian Zheng', *Meng-huai $\mathrm{Wu}^{1,2}$, A. Kharicha ${ }^{1,2}$, and A. Ludwig' \\ 1. Chair of Simulation and Modelling of Metallurgical Processes, Montanuniversitaet Leoben, Leoben, Austria \\ 2. Christian Doppler Laboratory for Advanced Process Simulation of Solidification and Melting, Department of Metallurgy, University of Leoben, \\ Leoben, Austria
}

\begin{abstract}
A volume average solidification model is extended to incorporate fragmentation as the source of equiaxed crystals during mixed columnar-equiaxed solidification. This study is to use this model to analyze the role of fragmentation in the formation of as-cast structure. Test simulations are made for the solidification of a model alloy $(\mathrm{Sn}-10 \mathrm{wt} . \% \mathrm{~Pb})$ with two different geometries. The first one is a $2 \mathrm{D}$ rectangular domain $\left(50 \times 60 \mathrm{~mm}^{2}\right)$ as cooled from the top boundary. Solidification starts unidirectionally as columnar structure from the top. The solute $(\mathrm{Pb})$ enriched interdendritic melt is heavier than the bulk melt, and sinks downwards, hence leads to solutal convection. Fragmentation phenomenon occurs near the columnar tip front. The fragments are transported out of the columnar region, and they continue to grow and sink, and finally settle down and pile up at the bottom. The growing columnar structure from the top and pile-up of equiaxed crystals from the bottom finally lead to a mixed columnar-equiaxed structure, in turn leading to a columnar-to-equiaxed transition (CET). The second geometry is a 3D plate, $100 \times 60$ $\times 10 \mathrm{~mm}^{3}$, as cooled laterally from one side. It was cast experimentally and analyzed for the as-cast structure. The equiaxed fragments are produced in the solidification front and transported into the bulk melt, leading to a special pattern of as-cast structure: columnar structure in the cool wall side and equiaxed structure in the upper left corner near the hot wall side, extending downwards to the middle bottom region. Numerically calculated as-cast structures agree with the experiment results.
\end{abstract}

Key words: macrostructure; interdendritic fluid flow; fragmentation
CLC numbers: TP391.99
Document code: $\mathrm{A}$
Article ID: 1672-6421(2017)05-321-06

$\mathrm{M}$ ore and more evidence has shown that the interdendritic fluid flow can facilitate the fragmentation by the mechanism of solute-driven remelting of dendrite arms ${ }^{[1-4]}$. On this base, a dendrite fragmentation criterion was proposed ${ }^{[5]}$. Additionally, the interdendritic flow is also a necessary condition for transport of the fragments out of the (columnar structure) mushy zone, and those fragments act as nuclei of equiaxed crystals $^{[6]}$. The current authors proposed a formula to incorporate fragmentation into a volume average model ${ }^{[7]}$. This work is to use this model to investigate the role of fragmentation in the formation of as-cast structure.

\section{*Prof. Meng-huai Wu}

He got his Ph.D degree in 2000 at the Foundry Institute, RWTH Aachen in Germany, and Habilitation (professorial certificate) in 2008 at Montanuniversitaet Leoben in Austria, and became the head of Christian Doppler Laboratory for "Advanced Process Simulation of Solidification and Melting" in 2010. His main research interests are the modeling and simulation of solidification and related phenomena during different casting processes.

E-mail: menghuai.wu@unileoben.ac.at

Received: 2017-08-15; Accepted: 2017-09-04
Two simulation examples are investigated. The first one takes the similar configuration of the experiment as performed by Cao et al. ${ }^{[8]}$. A 2D cavity, as initially filled with aqueous ammonium chloride $\left(\mathrm{NH}_{4} \mathrm{Cl}-\mathrm{H}_{2} \mathrm{O}\right)$, is cooled from top unidirectionally. The columnar structure grows from the top; the thermal-solutal convection causes the fragmentation; equiaxed crystals as grown from the fragments sediment at the bottom; finally a mixed columnar (top region) and equiaxed (bottom region) structure is developed. The second simulation example is based on a laboratory benchmark ${ }^{[9,10]}$. A plate casting of $\mathrm{Sn}-10 \mathrm{wt} . \% \mathrm{~Pb}$ alloy is cooled laterally. The columnar structure grows initially from the cool side; fragmentation occurs in the front of the columnar structure; the thermal-solutal convection transports from fragments to the other side, leading to a special pattern of mixed columnar (cool side) and equiaxed structure.

\section{Fragmentation formulation}

A three-phase mixed columnar-equiaxed solidification 
model was described previously ${ }^{[11,12]}$. The so-called three phases are the liquid, equiaxed and columnar. Their volume fractions are $f_{1}, f_{\mathrm{e}}$ and $f_{\mathrm{c}}$ with $f_{\mathrm{l}}+f_{\mathrm{e}}+f_{\mathrm{c}}=1$. Both the liquid and equiaxed phases are moving phases, while the columnar phase is assumed to be rigid and stationary. A dendritic equiaxed crystal is presumed and it is described by an equiaxed grain envelope, which includes the solid 'dendrite' and the inter-dendritic melt. The ratio of the volume of solid 'dendrite' to the volume of the equiaxed grain envelope is predefined $f_{\mathrm{si}}$. In this study, $f_{\mathrm{si}}$ is set as a constant value $(0.5)$. When $f_{\mathrm{e}}^{\text {Env }}\left(=f_{\mathrm{e}} / f_{\mathrm{si}}\right)$ reaches the hard blocking criterion, which is set as 0.49 at the columnar tip front, the columnar-to-equiaxed transition (CET) occurs. Once $f_{\mathrm{e}}^{\text {Env }}$ exceeds the packing limit (0.637), equiaxed crystals will build a stationary network

Fragments can be produced by the 'homogenous' remelting. Based on idea on the remelting-induced fragmentation ${ }^{[7]}$, following formulation for the fragmentation-induced mass transfer rate from the columnar phase to the equiaxed phase is suggested:

$$
M_{\mathrm{ce}}=-\gamma \cdot\left(\vec{u}_{\ell}-\vec{u}_{\mathrm{c}}\right) \cdot \nabla c_{\ell} \cdot \rho_{\mathrm{e}}
$$

$\vec{u}_{\ell}$ and $\vec{u}_{\mathrm{c}}$ are velocities of the melt and columnar structure; $\rho_{\mathrm{e}}$ is the density of equiaxed crystals. Fragmentation occurs only with remelting, i.e. for the case of $M_{\mathrm{ce}}>0.0$. For the case of solidification (calculated $M_{\text {ce }}$ has a negative value), we set $M_{\text {ce }}$ $=0.0$, i.e. no fragmentation should occur. Here a fragmentation coefficient, $\gamma$, is assigned to bridge the unknown correlation between fragmentation induced mass transfer rate and the increase rate of constitutional supersaturation caused by the interdendritic flow. All other unknown contributing factors for the remeltinginduced fragmentation such as the curvature effect of the dendrites, latent heat induced thermal fluctuation, diffusion in the interdendritic melt, etc. are included in the single coefficient $\gamma$.

It is assumed that the fragment is globular (spherical). The diameter of the fragment is proportional to the secondary dendrite arm space and the volume fraction of the columnar phase: $d_{\mathrm{e} \text { frag }}^{0}=\lambda_{2} f_{\mathrm{c}}$. Hence the rate of the fragment production can be calculated as:

$$
N_{\text {frag }}=M_{\mathrm{ce}} /\left[\rho_{\mathrm{e}} \cdot \frac{\pi}{6}\left(d_{\mathrm{e}, \mathrm{frag}}^{0}\right)^{3}\right]
$$

Transport of the number density of the equiaxed crystals, $n_{\mathrm{eq}}$, must be calculated with

$$
\frac{\partial}{\partial t} n_{\mathrm{eq}}+\nabla \cdot\left(\vec{u}_{\mathrm{e}} n_{\mathrm{eq}}\right)=N_{\text {frag }}
$$

by considering a source term $N_{\text {frag, }}$, which refers to the source of equiaxed crystals by fragmentation. Heterogeneous nucleation and the death of equiaxed crystals by dissolution (remelting) are here ignored.

A model alloy $\mathrm{Sn}-10 \mathrm{wt} . \% \mathrm{~Pb}$ is chosen for this study. Thermodynamic data and thermal physical properties of

\begin{tabular}{|c|c|c|c|c|}
\hline Properties & Symbol & Units & Value & Ref. \\
\hline Nominal concentration & $c_{0}$ & 1 & 0.1 & \\
\hline Liquidus temperature & $T_{\text {liq }}$ & $\mathrm{K}$ & 492.14 & [13] \\
\hline $\begin{array}{c}\text { Melting point of solvent } \\
\text { at } c_{0}=0\end{array}$ & $T_{\mathrm{f}}$ & $\mathrm{K}$ & 505 & [13] \\
\hline Eutectic composition & $c_{\mathrm{eu}}$ & 1 & 0.381 & [13] \\
\hline Eutectic temperature & $T_{\text {eu }}$ & $\mathrm{K}$ & 456 & [14] \\
\hline Liquidus slope & $m$ & $\mathrm{~K}$ & -128.6 & [13] \\
\hline $\begin{array}{l}\text { Equilibrium partition } \\
\text { coefficient }\end{array}$ & $m$ & 1 & 0.0656 & [13] \\
\hline Reference density & $\rho_{\text {ref }}$ & $\mathrm{kg} \cdot \mathrm{m}^{-3}$ & 7000 & [13] \\
\hline Equiaxed density & $\rho_{\mathrm{e}}$ & $\mathrm{kg} \cdot \mathrm{m}^{-3}$ & 7304 & [17] \\
\hline Specific heat & $\begin{array}{l}c_{p}^{\prime} \\
c_{p} \\
c_{p} \\
c_{p}\end{array}$ & $\mathrm{~J} \cdot \mathrm{kg}^{-1} \cdot \mathrm{K}^{-1}$ & 260 & [13] \\
\hline Thermal conductivity & $\begin{array}{l}k_{1} \\
k_{\mathrm{e}} \\
k_{\mathrm{c}}\end{array}$ & $\mathrm{W} \cdot \mathrm{m}^{-1} \cdot \mathrm{K}^{-1}$ & 55.0 & [13] \\
\hline Latent heat & $L$ & $\mathrm{~J} \cdot \mathrm{kg}^{-1}$ & $6.1 \times 10^{4}$ & [13] \\
\hline Viscosity & $\mu$ & $\mathrm{kg} \cdot \mathrm{m}^{-1} \cdot \mathrm{s}^{-1}$ & $1.0 \times 10^{-3}$ & [13] \\
\hline $\begin{array}{l}\text { Liquid thermal expansion } \\
\text { coefficient }\end{array}$ & $\beta_{\mathrm{T}}$ & $\mathrm{K}^{-1}$ & $6.0 \times 10^{-5}$ & [13] \\
\hline $\begin{array}{l}\text { Liquid solutal expansion } \\
\text { coefficient }\end{array}$ & $\beta_{c}$ & wt. $\%^{-1}$ & $-5.3 \times 10^{-3}$ & [13] \\
\hline $\begin{array}{c}\text { Primary dendritic arm } \\
\text { spacing }\end{array}$ & $\lambda_{1}$ & $\mathrm{~m}$ & $1.3 \times 10^{-3}$ & [13] \\
\hline $\begin{array}{l}\text { Second dendritic arm } \\
\text { spacing }\end{array}$ & $\lambda_{2}$ & $\mathrm{~m}$ & $0.65 \times 10^{-4}$ & [13] \\
\hline Diffusion coefficient (liquid) & $D$ & $\mathrm{~m}^{2} \cdot \mathrm{s}^{-1}$ & $4.5 \times 10^{-9}$ & [13] \\
\hline Diffusion coefficient (solid) & $D_{\mathrm{c}} D_{\mathrm{e}}$ & $\mathrm{m}^{2} \cdot \mathrm{s}^{-1}$ & $1 \times 10^{-12}$ & [13] \\
\hline Initial temperature & $T_{0}$ & $\mathrm{~K}$ & 492.14 & [13] \\
\hline Heat transfer coefficient & $h$ & $\mathrm{~W} \cdot \mathrm{m}^{-2} \cdot \mathrm{K}^{-1}$ & 400 & [13] \\
\hline External temperature & $T_{\mathrm{EXT}}$ & $\mathrm{K}$ & 298 & [13] \\
\hline Gibbs Thomson coefficient & $\Gamma$ & $\mathrm{m} \cdot \mathrm{K}$ & $6.5 \times 10^{-8}$ & [13] \\
\hline Fragmentation coefficient & $r$ & 1 & 0.1 & \\
\hline
\end{tabular}
alloy $\mathrm{Sn}-10 \mathrm{wt} . \% \mathrm{~Pb}$ are available, as listed in Table 1. A
Table 1: Material properties/data for alloy $\mathrm{Sn}-10 \mathrm{wt} . \% \mathrm{~Pb}$

linearized $\mathrm{Pb}-\mathrm{Sn}$ binary phase diagram, with a constant solute redistribution coefficient $k$ and a constant liquidus slope $m$, is used. The solidification model is developed within the framework of the CFD software ANSYS-Fluent version 14.5.

\section{Results and discussion}

\subsection{Simulation of a 2D test case}

A $2 \mathrm{D}$ cavity is configured in Fig. 1 . The configuration is similar to the experiment of Cao et al. ${ }^{[8]}$, but a different alloy $(\mathrm{Sn}-10$ wt.\%Pb) is considered. Density difference between equiaxed crystals and liquid is set as $304 \mathrm{~kg} \cdot \mathrm{m}^{-3}{ }^{[17]}$. Heat is only extracted through the top wall with a heat transfer coefficient, $h=400 \mathrm{~W} \cdot \mathrm{m}^{-2} \cdot \mathrm{K}^{-1}$, while other walls are set as adiabatic boundary. As a closed domain is calculated and no volume shrinkage is considered, the Boussinesq approximation is made for the thermo-solutal convection and crystal sedimentation. The cavity is initially filled with the stationary melt of its liquidus temperature. 


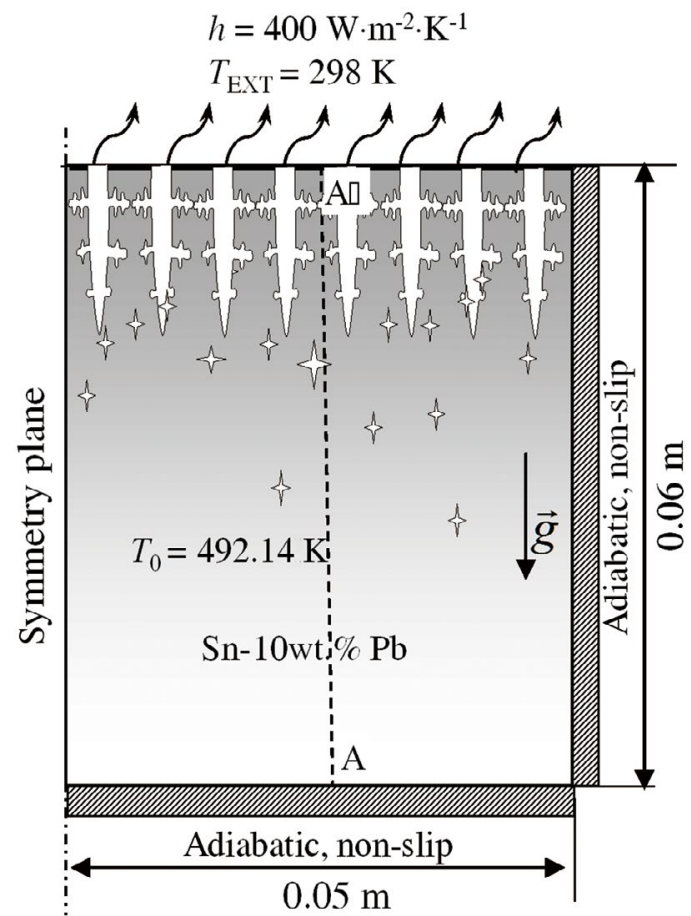

Fig. 1: Configuration of 2D cavity
Figure 2 shows the solidification sequence at a $75 \mathrm{~s}$ for the cavity. Here a constant fragmentation coefficient $(\gamma=0.1)$ is taken following a parameter study ${ }^{[7]}$. With the initiation of cooling, the growth of columnar trunks and thermal-solutal convection begin from the top. The bulk melt begins to move due to solutal or thermal buoyancy. Some convection cells can penetrate into the mushy zone. Furthermore, fragmentation is shown by the $N_{\text {frag }}$ contouroccurs in the mushy zone. Equiaxed crystals start growing and sinking; however, their motion is influenced by the melt flow through the drag force, as seen schematically in Fig. 2(a). The top mushy zone (columnar) extends to approximately $1 / 3$ of the domain [Fig. 2(b)]. A large vortex of melt flow and some small convection cells form in the bulk and near the columnar tip front regions, penetrating into the mushy zone (till $f_{\mathrm{e}} \sim 0.3$ ). The melt flow has a significant impact on the velocity field of the equiaxed crystals. Both the melt flow and motion of equiaxed crystals have similar velocity magnitude. As $f_{\mathrm{e}}$ reaches the packing limit in the bottom region, the equiaxed phase stops moving. A second mushy zone with packed equiaxed crystals develops from the bottom [Fig. 2(c)]. Once the equiaxed is fixed, columnar phase has the possibility to grow, competing with the growth of the equiaxed phase. The fragmentation continues near the columnar tip front [Fig. 2(d)],
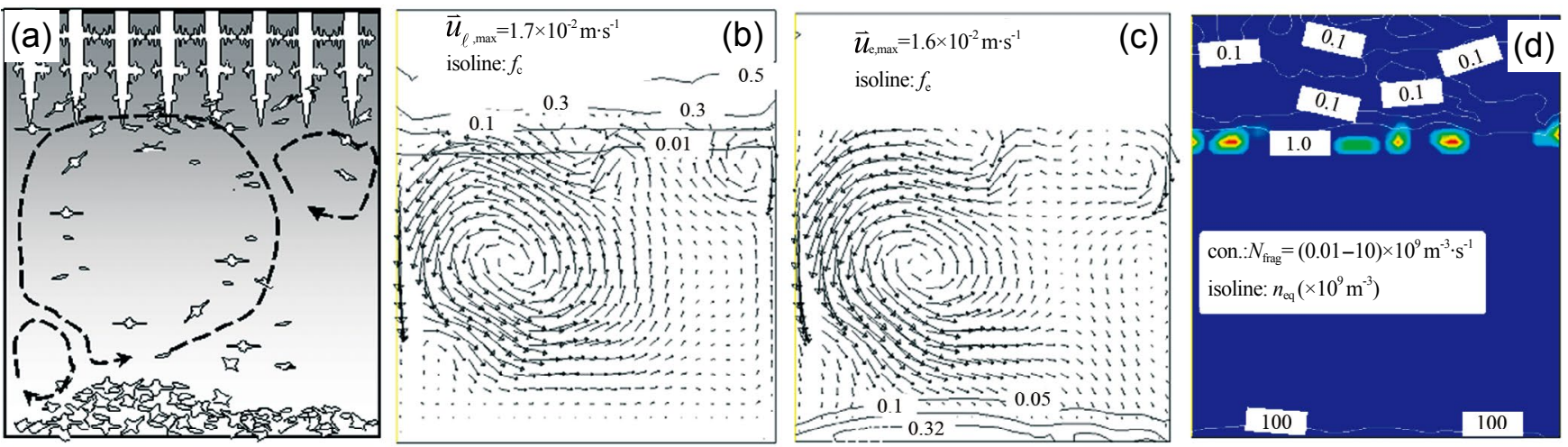

Fig. 2: Solidification sequence at $75 \mathrm{~s}$ for cavity: (a) schematic of different solidification regions and flow pattern, (b) calculated liquid velocity overlaid with $f_{\mathrm{c}}$ isoline, (c) equiaxed velocity overlaid with $f_{\mathrm{e}}$ isoline, and (d) contour of production rate of fragments $\left(N_{\text {frag }}\right)$ overlaid with isoline of number density of equiaxed crystals $\left(n_{\text {eq }}\right) . N_{\text {frag }}$ is presented in color scale with blue for minimum $\left(1 \times 10^{7} \mathrm{~m}^{-3}\right)$, and red for maximum $\left(1 \times 10^{10} \mathrm{~m}^{-3}\right)$

supplying equiaxed nuclei continuously. The maximum number density can reach a magnitude of $10^{11} \mathrm{~m}^{-3}$.

The extension of the upper columnar mushy zone and the pile-up of the equiaxed mushy zone meet at approximately one-third height of the domain. The growth of the columnar tip front is blocked by the equiaxed grain mechanically, that is, columnar-to-equiaxed transition (CET) occurs. The entire solidification sequence ends at $580 \mathrm{~s}$, and the remaining melt in the mushy zone solidifies as eutectic phases below temperature $T_{\text {eu }}$. The final as-cast structure is shown in Fig. 3. The downward movement of fragments/equiaxed crystals leads to an equiaxed zone in the lower part of the cavity. In the upper part of the benchmark is mainly composed of columnar phase. There is a clear CET in the middle of the cavity; near the CET there is the location where the solidification ends with most amount of eutectic phases. The CET occurs at about $300 \mathrm{~s}$, when the tip of columnar dendrite is blocked by the equiaxed crystals.

The numerically calculated solidification sequence and ascast structure agrees qualitatively with the aqueous ammonium chloride experiment ${ }^{[8]}$. It was experimentally observed that the equiaxed crystals moved away from the front of the columnar mushy zone and settled to form an equiaxed region at the bottom, leading to CET in the middle of the cavity.

\subsection{Simulation of a laboratory benchmark in 3D}

The dimensions, boundary, initial and other process conditions for the simulation taken from the experiment performed in the SIMAP/EPM laboratory ${ }^{[10]}$, are shown in Fig. 4 . The calculation domain in 3D and boundary conditions are shown Fig. 4(a). The melt is assumed to be homogeneous before solidification. The temperature difference between the two lateral sides is $40 \mathrm{~K}$, and the cooling rate $\mathrm{CR}=0.03 \mathrm{~K} \cdot \mathrm{s}^{-1}$ for both cool and hot walls [Fig. 

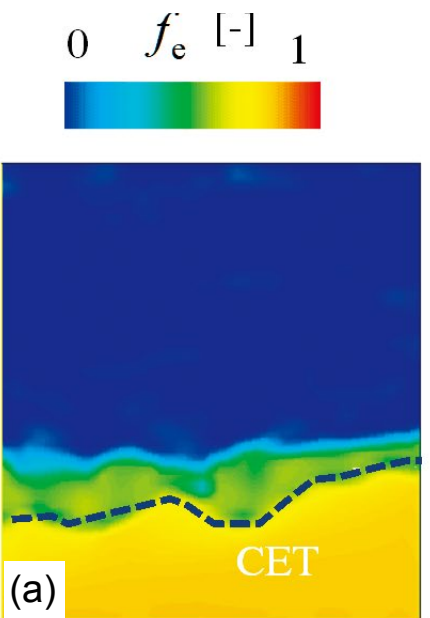
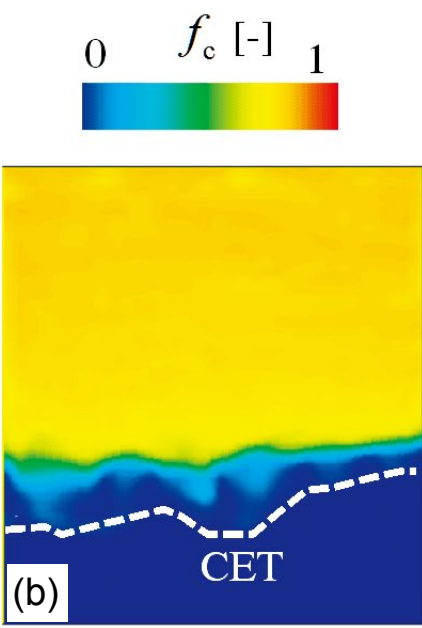
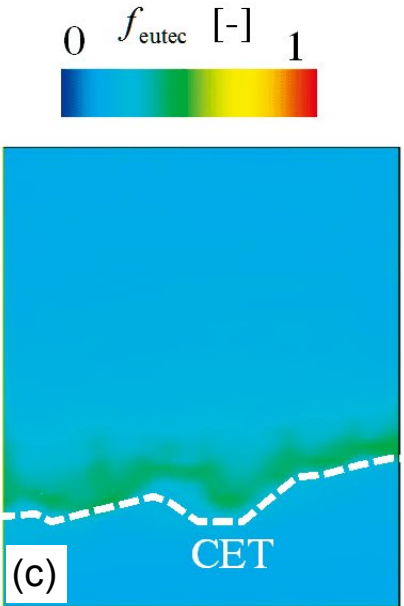

Fig. 3: Numerically calculated as-cast structure: contours of equiaxed volume fraction (a), columnar volume fraction (b) and eutectic volume fraction (c)
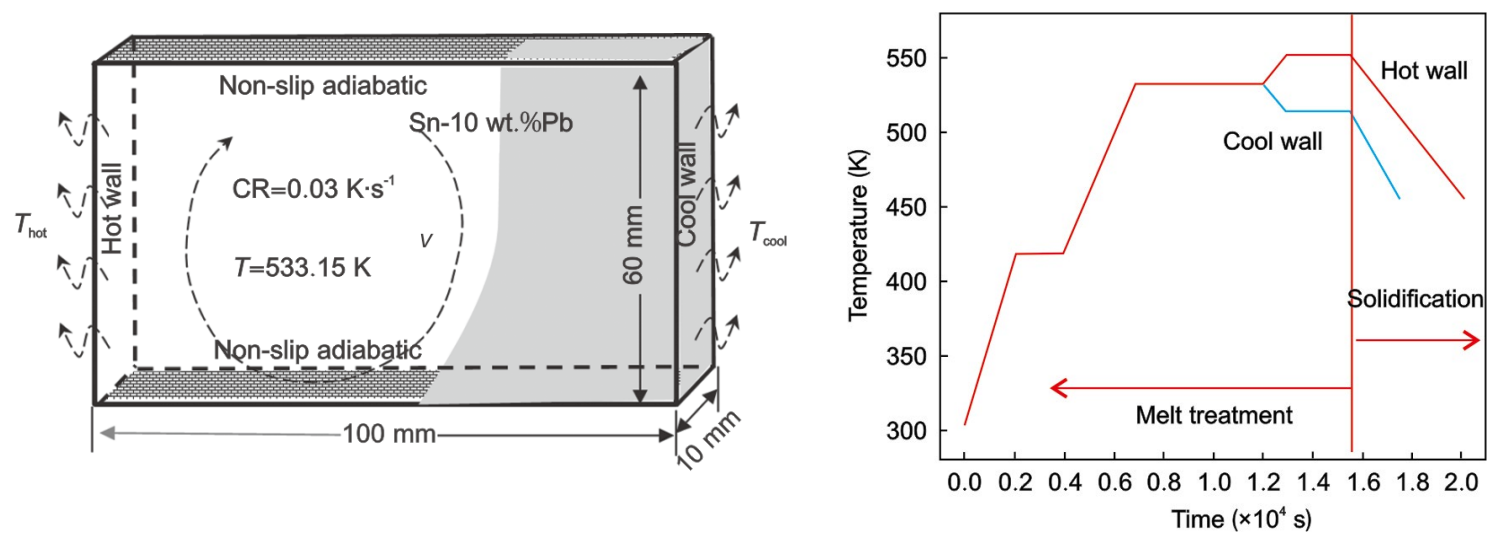

Fig. 4: Configuration of laboratory benchmark (a) and temperature history of hot wall and cool wall (b)

4(b)]. The liquid density is considered to be a function of the melt concentration ${ }^{[13,17]}$. Permeability in the mushy zone is set to be anisotropic ${ }^{[18]}$.

Figure 5 shows the solidification sequence at $1,135 \mathrm{~s}$ for the benchmark. The fragmentation of dendrite is considered as the only source of equiaxed crystals, therefore the presence of columnar is the precondition of equiaxed crystals. Equiaxed crystals are produced near the solidification front from cool wall (right). There is a clockwise circulation during solidification [Fig. 5(a)-(b)]. The newly-born fragments will float into the bulk-melt region. When the bulk melt temperature is higher than liquidus temperature, those crystals are melted. When the bulk melt is cooled to below liquidus temperature, those crystals survive and grow into the equiaxed structure. Another interesting point is that the melt is gradually enriched with solute $(\mathrm{Pb})$ during the late stage of solidification, and when the density of the melt becomes larger than the solid equiaxed crystals, the equiaxed crystals float upwards [Fig. 5(c)-(d)].

The as-cast macrostructure on the center plane is shown in Fig. 6. Figure 7 shows the spatial distribution of different phases in the as-solidified plate. Simulation results show that the right side of the plate is dominantly occupied by columnar phase [Fig. 6(a)], and some eutectic phases are located in leftbottom region near the hot wall [Fig. 6(b)]. There is also little fraction of eutectic phase embedded in columnar phases. The equiaxed crystals are concentrated in the upper left corner and this region extends to the middle-bottom region of the plate [Fig. 6(c)]. The equiaxed zone is indicated by the space between bold line and dashed line. The bold line is the boundary of columnar and equiaxed phase i.e. CET. The dashed line indicated the boundary between equiaxed phase and eutectic. Figure 6(d) shows the experiment result of the as-cast structure. The general appearance is similar to the simulation one. Columnar dendrites exist in the right side and equiaxed crystals in the upper right region. However, a small second columnar region is observed in the left-bottom corner region near the hot wall but the simulation result show eutectic phases there. The simulation may overestimate $\mathrm{Pb}$ concentration in the rest melt during late stage of solidification. It requires further validation from the metallography analysis.

\section{Conclusions}

A fragmentation formulation by the mechanism of solutedriven remelting of the dendrite arms is integrated into a mixed columnar-equiaxed solidification model. Demonstratively, this model is used to simulate the solidification process of two test cases. 


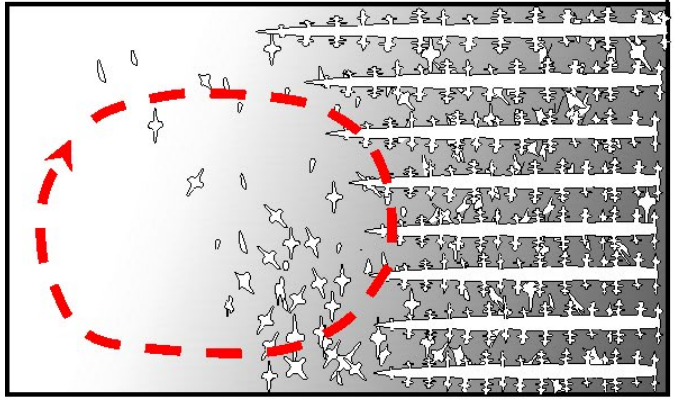

(a)

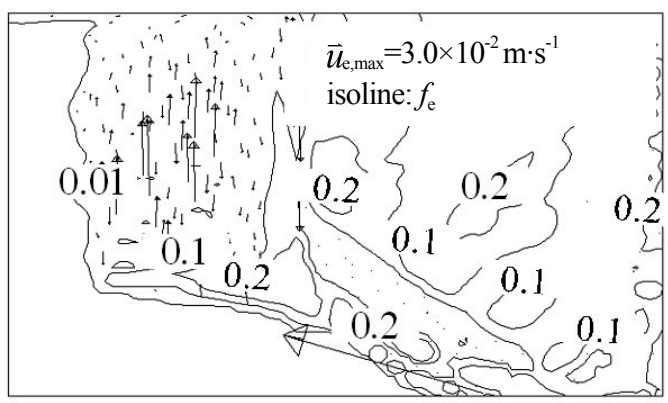

(c)

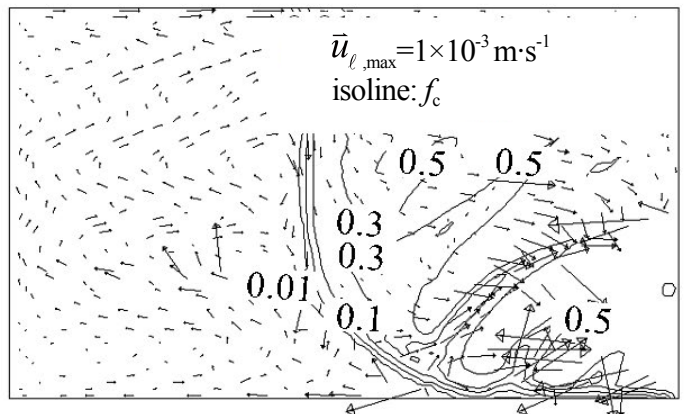

(b)

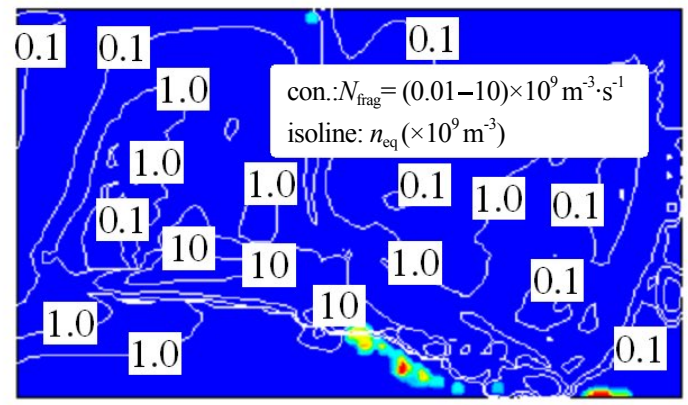

(d)

Fig. 5: Solidification sequence at 1,135 s for laboratory benchmark: (a) schematic of different solidification regions and flow pattern, (b) calculated liquid velocity overlaid with $f_{c}$ isoline, (c) equiaxed velocity overlaid with $f_{\mathrm{e}}$ isoline, and (d) contour of production rate of fragments $\left(N_{\text {frag }}\right)$ overlaid with isoline of number density of equiaxed crystals $\left(n_{\text {eq }}\right)$. $N_{\text {frag }}$ is presented in color scale with blue for minimum $\left(1 \times 10^{7} \mathrm{~m}^{-3}\right)$, and red for maximum $\left(1 \times 10^{10} \mathrm{~m}^{-3}\right)$
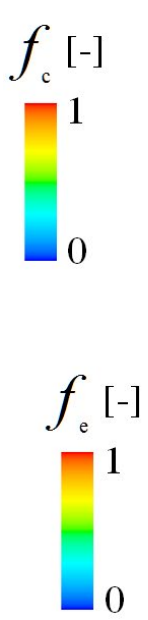

0

(1)

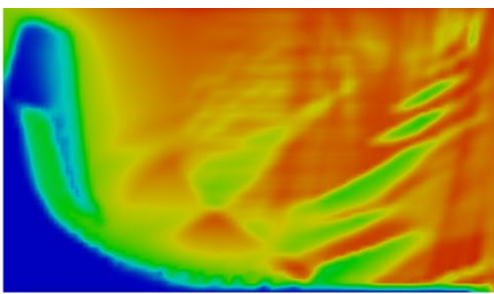

(a)

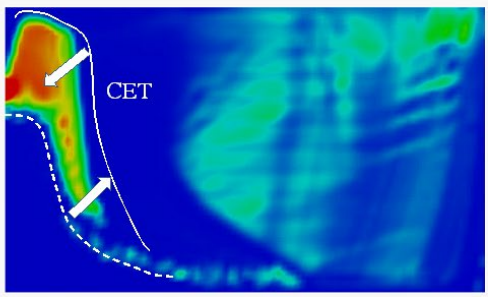

(c)

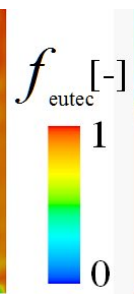

0

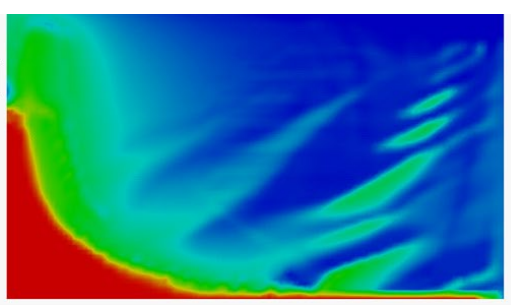

(b)

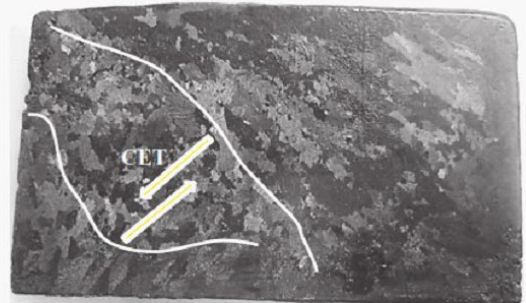

(d)

Fig. 6: Macrostructure on central cross section of as-solidified plate: simulation results of columnar volume fraction distribution (a), eutectic volume fraction (b), equiaxed volume fraction (c); and experimental result of as-cast structure (d)

The first case with $\mathrm{Sn}-10 \mathrm{wt} . \% \mathrm{~Pb}$ melt solidifying downwards in a $2 \mathrm{D}$ domain $\left(50 \times 60 \mathrm{~mm}^{2}\right)$ is simulated. A reasonable solidification sequence is calculated. Solidification starts unidirectionally as columnar structure from the top; fragmentation as caused by the thermal-solutal convection occurs near the columnar tip front; the equiaxed crystals as grown from the fragments finally settle down and pile up at the bottom, leading to a mixed equiaxed (bottom region) and columnar (top) structure. The simulation result agrees qualitatively with what was observed experimentally by Cao et al. ${ }^{[8]}$. This test case demonstrates that the improved mixed columnar-equiaxed solidification model is able to calculate the phenomena such as dendrite fragmentation, transport of the fragments and the equiaxed crystals, formation of columnar-toequiaxed transition (CET) and the final as-cast structure.

The second case takes the same configuration of a laboratory benchmark ${ }^{[10]}$, i.e. a plate casting of the $\mathrm{Sn}-10 \mathrm{wt} . \% \mathrm{~Pb}$ alloy as cooled laterally. Solidification as columnar structure starts from the mold wall of cool side; fragmentation occurs near the columnar tip front; the equiaxed fragments as produced in the solidification front are transported into the bulk melt, leading to a special pattern of as-cast structure: columnar structure in the cool 

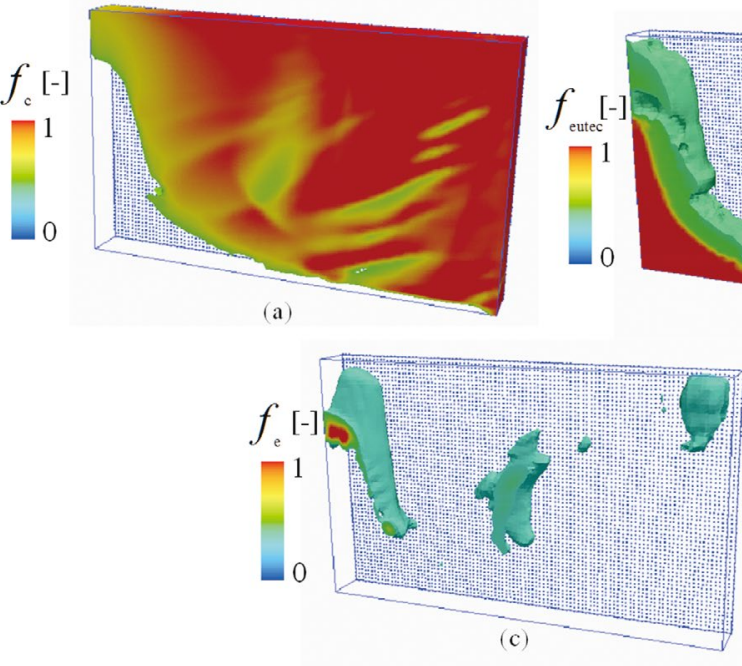

Fig. 7: Spatial distribution of as-cast structure (simulation result): (a) columnar volume fraction, (b) eutectic volume fraction and (c) equiaxed volume fraction. Distributions for different phase regions are presented by their isosurface of volume fraction $f=0.25$ wall side and equiaxed structure in the upper left corner near the hot wall side, extending downwards to the middle bottom region. Numerically calculated phase distribution agrees satisfactorily with the postmortem analysis of the as-cast structure of the laboratory benchmark. This simulation-experiment agreement has partially verified the numerical model.

The numerical model provides a valuable tool to analyze the process of mixed columnar-equiaxed solidification, where the equiaxed crystals originate from fragmentation.

\section{References}

[1] Kattamis T Z, Coughlin J and Flemings M C. Influence of coarsening on dendrite arm spacing of aluminum-copper alloys. Transactions of the Metallurgical Society of Aime, 1967, 239(10): 1504-1511.

[2] Mathiesen R, Arnberg L, Bleuet $P$, et al. Crystal fragmentation and columnar-to-equiaxed transitions in $\mathrm{Al}-\mathrm{Cu}$ studied by synchrotron X-ray video microscopy. Metallurgical and Materials Transactions A, 2006, 37(8): 2515-2524.

[3] Montgomery $\mathrm{W}$ and Incropera F. Fragmentation of dendritic crystals during solidification of aqueous ammonium chloride. Experimental Heat Transfer, 1998, 11(1): 59-86.

[4] Yasuda H, Yamamoto $Y$, Nakatsuka N, et al. In situ observation of nucleation, fragmentation and microstructure evolution in $\mathrm{Sn}-\mathrm{Bi}$ and $\mathrm{Al}-\mathrm{Cu}$ alloys. International Journal of Cast Metals Research, 2008, 21(1-4): 125-128.

[5] Campanella T, Charbon C and Rappaz M. Grain refinement induced by electromagnetic stirring: A dendrite fragmentation criterion. Metallurgical and Materials Transactions A, 2004, 35(10): 3201-3210.

[6] Pilling $\mathrm{J}$ and Hellawell A. Mechanical deformation of dendrites by fluid flow. Metallurgical and Materials Transactions A, 1996, 27(1): 229-232.

[7] Zheng $\mathrm{Y}$, Wu M, Kharicha A, Ludwig A. Incorperation of fragmentation into a volume average solidification model. Modelling and Simulation In Materials Science and Engineering, 2017, in press: http://doi.org/10.1088/1361-651X/aa86c5.

[8] Gao J W and Wang C Y. Effects of grain transport on columnar to equiaxed transition in dendritic alloy solidification. Modeling of Casting, Welding and Advanced Solidification Processes VIII, 1998: 425-432.

[9] Boussaa R, Hachani L, Budenkova O, et al. Macrosegregations in $\mathrm{Sn}-3 \mathrm{wt} \% \mathrm{~Pb}$ alloy solidification: Experimental and 3D numerical simulation investigations. International Journal of Heat and Mass Transfer, 2016, 100: 680-690.

[10] Hachani L, Zaidat $K$ and Fautrelle $Y$. Experimental study of the solidification of $\mathrm{Sn}-10 \mathrm{wt} . \% \mathrm{~Pb}$ alloy under different forced convection in benchmark experiment. International Journal of Heat and Mass Transfer, 2015, 85(0): 438-454.

[11] Wu M and Ludwig A. A three-phase model for mixed columnar-equiaxed solidification. Metallurgical and Materials Transactions A, 2006, 37A(5): 1613-1631.

[12] Wu M and Ludwig A. Using a three-phase deterministic model for the columnar-to-equiaxed transition. Metallurgical and Materials Transactions A, 2007, 38A(7): 1465-1475.

[13] Bellet $M$, Combeau H, Fautrelle $Y$, et al. Call for contributions to a numerical benchmark problem for 2D columnar solidification of binary alloys. International Journal of Thermal Sciences, 2009, 48(11): 2013-2016.

[14] Ahmad N, Rappaz J, Desbiolles J L, et al. Numerical simulation of macrosegregation: a comparison between finite volume method and finite element method predictions and a confrontation with experiments. Metallurgical and Materials Transactions A, 1998, 29(2): 617-630.

[15] Klassen $\mathrm{M}$ and Cahoon $\mathrm{J}$. Interdiffusion of $\mathrm{Sn}$ and $\mathrm{Pb}$ in liquid $\mathrm{Pb}-\mathrm{Sn}$ alloys. Metallurgical and Materials Transactions A, 2000, 31(5): 1343-1352.

[16] Cadirli $E$ and Gündüz $\mathrm{M}$. The directional solidification of $\mathrm{Pb}-\mathrm{Sn}$ alloys. Journal of Materials Science, 2000, 35(15): 3837-3848.

[17] Rocha O L, Siqueira C A and Garcia A. Heat flow parameters affecting dendrite spacings during unsteady-state solidification of $\mathrm{Sn}-\mathrm{Pb}$ and $\mathrm{Al}-\mathrm{Cu}$ alloys. Metallurgical and Materials Transactions A, 2003, 34(4): 995-1006.

[18] Schneider M and Beckermann C. A numerical study of the combined effects of microsegregation, mushy zone permeability and fllow, caused by volume contraction and thermosolutal convection, on macrosegregation and eutectic formation in binary alloy solidification. International Journal of Heat and Mass Transfer, 1995, 38(18): 3455-3473. 